ICAMS $2016-6^{\text {th }}$ International Conference on Advanced Materials and Systems

\title{
DETERMINATION AND MAPPING OF TEAR LOAD, TENSILE STRENGTH AND EXTENSION VALUES ON OVERALL AREA OF GOATSKIN LEATHERS
}

\author{
MEHMET METE MUTLU, NILAY ORK, BIRGUL KAYA, SAMET GUNESEL \\ Ege University, Engineering Faculty, Leather Engineering Department, Bornova, Izmir, Turkiye, \\ mete.mutlu@ege.edu.tr
}

\begin{abstract}
Leather can be defined as a protein based fibrillary network, which consists mainly from collagen. The look, length and thickness of these fiber bundles are different in various organs of the body. Thus, leather is not a uniform material from a structural perspective and the properties of a leather piece depend on the position and direction over its area. The aim of this study was to measure some physical properties of goatskin leathers such as tear load, tensile strength and extension over the whole area and to draw maps showing regional variations. For this aim, whole the surface areas of 12 goatskin leathers have been sampled. Thickness, tear load, tensile strength and extension at break values of each sample have been measured and recorded. Then maps were drawn by using MATLAB (Matrix Laboratory) software that allows matrix manipulations, plotting of functions and data. The findings showed that the tear load, tensile strength and extension properties change directionally and locational over the area of the leather. These maps will provide information for usage area of the leathers especially for cutting in footwear production.
\end{abstract}

Keywords: leather, goatskin, physical properties

\section{INTRODUCTION}

Depending on the fields of use, specific performance characteristics are expected from the leathers (Urbanija et al., 2004). Especially special mechanical performance properties are expected from shoes, which carries the body weight and related with comfort and health.

When choosing a good leather product and evaluating its quality, people always pay close attention to its handle character, although its physical-mechanical properties contribute to capability of withstanding wear (Xiao-Lei et al., 2006). Also the shoe upper leathers are affected by foot movements and must protect foot from outer impacts. Physical resistance of shoe upper leathers should be high if the quality is desired.

Leather processing can simply be defined as, modification of hides/skins by a sequence of chemical and physical treatments. Various physical, chemical and fastness properties are required from leather products depending on their field of use (Ork et al., 2014). Leather is an intermediate industrial product with numerous applications in downstream sectors. It can be cut and assembled into shoes, clothing, leather goods, furniture and many other items of daily use (Joseph et al., 2009). However leather is not a uniform material from a structural perspective. The physical properties of leather change depending on the animal type and the animal individually. Furthermore these properties exhibit variations in different parts over the leather area (Mutlu et al., 2014).

The aim of this study is to measure physical properties such as tear load, tensile strength and \% extension of goat shoe upper leathers over the whole areas in both directions: perpendicular and parallel to the backbone and to compare the results and to draw maps showing distributions of physical properties that can give information on cutting of leathers for shoe production with the aim of achieving high quality. 


\section{MATERIAL AND METHOD}

\section{Material}

- 12 chromium tanned goatskin leathers obtained from a shoe upper leather manufacture company,

- Hydraulic press and press knives for cutting leather specimens,

- Satra-Thickness gauge for thickness measurement of leather specimens,

- Shimadzu AG-IS Tensile Tester and Trapezium-2 software for testing physical properties,

- MATLAB R2012b software for drawing maps of strengths and extensions.

\section{Method}

The test samples were conditioned according to TS EN ISO 2419 , at $23 \pm 2{ }^{\circ} \mathrm{C}$ and $50 \% \pm 5 \mathrm{RH}$ (Anonymous 2015). The thicknesses of test samples were measured according to TS 4117 EN ISO 2589 standard (Anonymous 2016a) by using SatraThickness gauge. Physical properties of leather samples were determined by using Shimadzu AG-IS Tensile Tester and Trapezium-2 software following standard test methods: TS EN ISO 3377-2 - Determination of tear load - Part 2: Double edge tear (Anonymous 2016b) and TS EN ISO 3376 - Determination of tensile strength and percentage extension (Anonymous 2012).

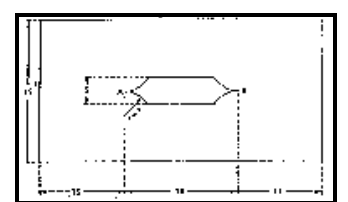

(a)

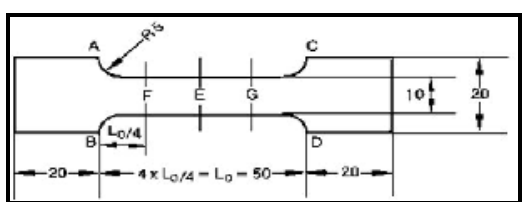

(b)

Figure 1. Dimensions of press knives used for tear load (a) and tensile strength/extension (b)

The samples were taken perpendicular to the backbone line from 3 leathers and parallel to the backbone line from the other 3 leathers for both tests. Numbers of samples are given in Table 1.

Each sample was coded regarding to its position over the leather area. Tear load, tensile strength and \% extension data were entered into MATLAB spreadsheet cell according to its original position. Then the maps of strengths and percentage of extensions were plotted by using the "Contour Plots-contourf" function in MATLAB.

Table 1. Sampling directions and number of samples for tear load (a), tensile strength and percentage of extension (b)

\begin{tabular}{lcc}
\hline Sampling Direction to Backbone & Number of Samples (a) & Number of Samples (b) \\
\hline Perpendicular 1 & 500 & 387 \\
Perpendicular 2 & 577 & 390 \\
Perpendicular 3 & 567 & 400 \\
Parallel 1 & 390 & 332 \\
Parallel 2 & 492 & 220 \\
Parallel3 & 565 & 217 \\
Total & 3091 & 1946 \\
\hline
\end{tabular}


ICAMS $2016-6^{\text {th }}$ International Conference on Advanced Materials and Systems

\section{RESULTS AND DISCUSSION}

The minimum, maximum and mean values of thickness and tear load measurements for the samples are given in Table 2. The mean thickness values are between 1.06$1.10 \mathrm{~mm}$. When the data are compared, it is seen that tear load results of perpendicular samples are higher than parallel samples. UNIDO recommends a minimum of $30 \mathrm{~N}$ of tear load for shoe upper leathers. The tear load results of goat shoe upper leathers are compatible with the acceptable quality standards advised by UNIDO (1996).

Table 2. Thickness and tear load of perpendicular and parallel samples

\begin{tabular}{llcccc}
\hline & & \multicolumn{2}{c}{ Perpendicular } & \multicolumn{2}{c}{ Parallel } \\
& & $\begin{array}{c}\text { Thickness } \\
(\mathrm{mm})\end{array}$ & $\begin{array}{c}\text { Tear load } \\
(\mathrm{N})\end{array}$ & $\begin{array}{c}\text { Thickness } \\
(\mathrm{mm})\end{array}$ & $\begin{array}{c}\text { Tear load } \\
(\mathrm{N})\end{array}$ \\
\hline 1 & Mean & 1.16 & 76.77 & 0.94 & 58.96 \\
& Min & 0.90 & 33.27 & 0.77 & 25.00 \\
& Max & 1.60 & 120.13 & 1.30 & 87.23 \\
& & & & & \\
& Mean & 1.02 & 77.73 & 1.19 & 74.84 \\
& Min & 0.82 & 36.45 & 0.98 & 43.01 \\
& Max & 1.35 & 109.89 & 1.80 & 102.27 \\
& & & & & \\
& Mean & 1.00 & 75.19 & 1.17 & 64.77 \\
& Min & 0.73 & 25.63 & 0.92 & 30.03 \\
& Max & 1.35 & 107.27 & 1.45 & 114.90 \\
Mean & & & & & \\
& Mean & 1.06 & 76.56 & 1.10 & 66.19 \\
& Min & 0.82 & 31.78 & 0.89 & 32.68 \\
& Max & 1.43 & 112.43 & 1.52 & 101.47 \\
\hline \multirow{4}{*}{} & & & & &
\end{tabular}

The minimum, maximum and mean values of thickness, tensile strength and percentage extension measurements for the samples are given in Table 3. The mean thickness of leather samples are between $0.92-1.03 \mathrm{~mm}$. When the data are compared, the tensile strength results of perpendicular samples are higher than parallel samples. UNIDO recommends a minimum $20 \mathrm{~N} / \mathrm{mm}^{2}$ of tensile strength of shoe upper leathers. The tensile strength results of goat shoe upper leathers are compatible with the acceptable quality standards advised by UNIDO (1996).

Tensile-elastic properties or elasticity is defined as a property where a body tends to recover to its original state after being deformed. If a body is affected by a force this can lead to certain stresses in the body causing its deformation, i.e. extension (Urbanija et al., 2004). The elastic properties of shoe materials are important in two ways. The first one is the extension of material with the feet movement which provides comfort to the user. The second one is the extension needed in production of shoes in lasting process. These extensions should be in limits so that no damage would occur in the shoe material.

It is observed that there is a significant difference in percentage of extension depending on the sampling direction (Table 3). The mean extension percent of parallel samples are \% 39.41 and higher than the mean extension percent of perpendicular samples, which is \% 28.68. Thanikaivelan et al. (2006) have investigated that maximum breaking load and percentage extension at break values of the shoe upper leather tested at various gauge lengths for the dumbbell specimens in both parallel and perpendicular 
Determination and Mapping of Tear Load, Tensile Strength and Extension Values on Overall Area of Goatskin Leathers

directions to the backbone and the percentage extension of perpendicular and parallel to the backbone found as $44 \%$ and $45 \%$ at $9.53 \mathrm{~cm}$ gauge length respectively.

Table 3. Thickness, tensile strength and percentage of extension of perpendicular and parallel samples

\begin{tabular}{llcccccc}
\hline & & $\begin{array}{c}\text { Perpendicular } \\
\text { Thickness } \\
(\mathrm{mm})\end{array}$ & $\begin{array}{c}\text { Tensile } \\
\text { strength } \\
\left(\mathrm{N} / \mathrm{mm}^{2}\right)\end{array}$ & $\begin{array}{c}\text { Extension } \\
(\%)\end{array}$ & $\begin{array}{c}\text { Thickness } \\
(\mathrm{mm})\end{array}$ & $\begin{array}{c}\text { Parallel } \\
\text { Tensile } \\
\text { strength } \\
\left(\mathrm{N} / \mathrm{mm}^{2}\right)\end{array}$ & $\begin{array}{c}\text { Extension } \\
(\%)\end{array}$ \\
\hline 1 & Mean & 0.87 & 24.812 & 33.08 & 1.12 & 18.09 & 37.93 \\
& Min & 0.70 & 6.24 & 11.28 & 0.93 & 6.28 & 10.25 \\
& Max & 1.24 & 42.65 & 107.96 & 2.21 & 32.29 & 86.53 \\
2 & & & & & & & \\
& Mean & 0.92 & 23.86 & 27.71 & 1.00 & 19.96 & 38.04 \\
& Min & 0.69 & 5.59 & 10.01 & 0.72 & 4.70 & 11.93 \\
& Max & 1.89 & 38.69 & 78.85 & 1.41 & 34.44 & 102.08 \\
& & & & & & & \\
& Mean & 0.98 & 23.42 & 25.26 & 0.99 & 22.35 & 42.26 \\
& Min & 0.80 & 4.59 & 8.37 & 0.71 & 6.40 & 15.35 \\
& Max & 1.35 & 39.09 & 79.15 & 1.27 & 37.22 & 125.36 \\
& & & & & & & \\
& Mean & 0.923 & 24.03 & 28.68 & 1.03 & 20.13 & 39.41 \\
& Min & 0.73 & 5.47 & 9.89 & 0.79 & 5.79 & 12.51 \\
& Max & 1.49 & 40.14 & 88.65 & 1.63 & 34.65 & 104.66 \\
\hline
\end{tabular}

The directions of maximum and minimum stretch in the area now recognized as the "Official Sampling Position" (OSP) run respectively parallel and perpendicular to the backbone. However across the rest of the hide the direction of minimum and maximum values varies. The maximum values run more or less in the direction of the hair follicle, as this roughly follows the direction of the underlying fiber structures (Daniels, 2007; Mutlu et al., 2014). The mean tensile strength values vary in the range of 5.47-40.14 $\mathrm{N} / \mathrm{mm}^{2}$ and $5.79-34.65 \mathrm{~N} / \mathrm{mm}^{2}$ for perpendicular and parallel samples respectively. This means 7 times strength variations over the area for the same leather. The tear load values vary in the range of $31.78-112.43 \mathrm{~N}$ and $32.68-101.47 \mathrm{~N}$ for perpendicular and parallel samples respectively. UNIDO standards are $20 \mathrm{~N} / \mathrm{mm}^{2}$ for tensile strength and for tear load $30 \mathrm{~N}$. So, the same leather can meet or fail the quality standards depending on the region of sampling.. Fig.2-4 shows the maps of the means of tear load, tensile strength and percentage of extension values over the area of whole goat skin leathers. 
ICAMS $2016-6^{\text {th }}$ International Conference on Advanced Materials and Systems

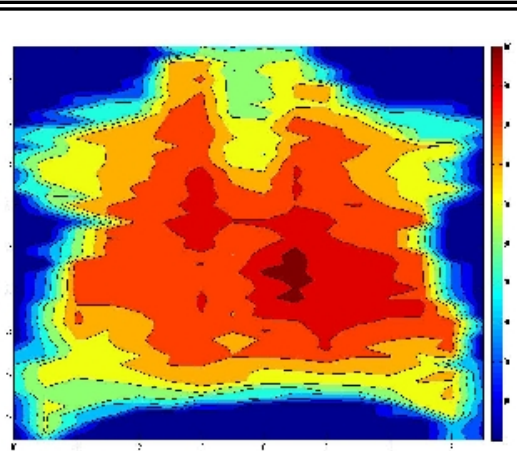

(a)

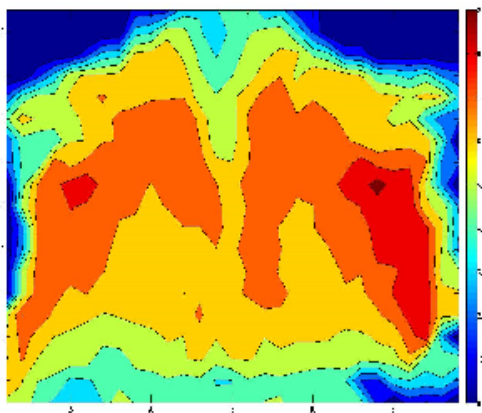

(b)

Figure 2. Perpendicular dimension (a), parallel dimension (b) of tear load

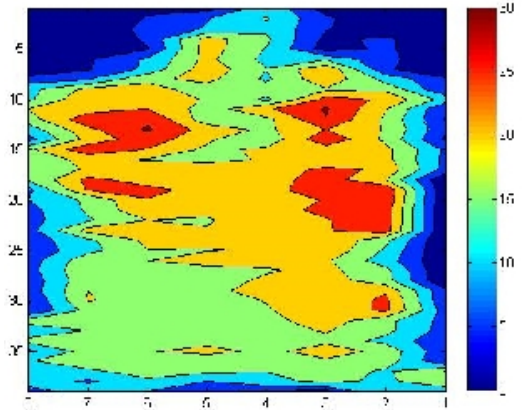

(a)

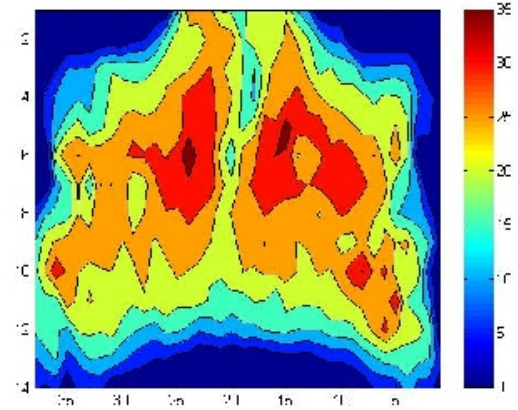

(b)

Figure 3. Perpendicular dimension (a), parallel dimension (b) of tensile strength

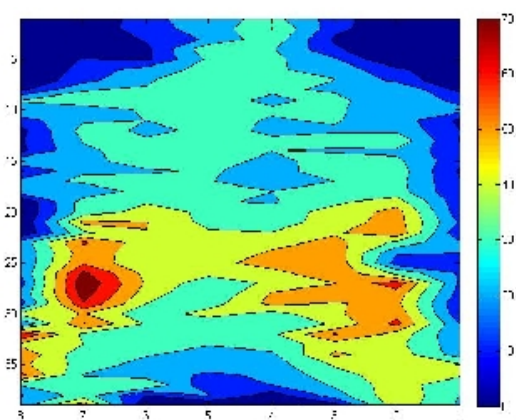

(a)

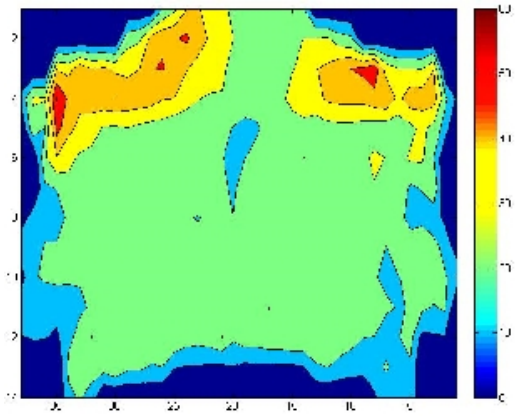

(b)

Figure 4. Perpendicular dimension (a), parallel dimension (b) of percentage of extension

\section{CONCLUSIONS}

From the results of this study following conclusions were concluded:

- Shoe upper goat leathers have different physical properties depending on the direction of sampling. Tear load and tensile strength are higher when the 
samples are perpendicular to the backbone line. However percentages of extension at break values are higher when the samples are parallel to the backbone.

- Shoe upper goat leathers have different physical properties depending on the location of sampling. Tear load, tensile strength and percentage of extension values can vary up to three, seven and ten times respectively depending on the sampling location.

- When the maps are observed, the tear load and tensile strength are higher at the sides of backbone line of leathers and decrease gradually moving to the edges. The backline, neck and tail areas are also weaker.

- The physical tests of leathers are done with the samples taken from standard sampling location (TS EN ISO 2418, 2006) but, even for a leather which can pass the quality tests, its weak areas can fail the quality.

- The pattern cutter should be aware of the change of leather properties depending on the cutting location and direction and should place the patterns considering the forces they would subject to during the usage. These maps of physical properties can be guiding for the shoe pattern cutters and thus provide information to make higher quality shoes.

\section{REFERENCES}

Anonymous (2006), TS EN ISO 2418 Leather - Chemical, physical and mechanical and fastness tests Sampling location, Turkish Standard (TSE), Ankara.

Anonymous (2012), TS EN ISO 3376 Leather - Physical and mechanical tests - Determination of tensile strength and percentage extension, Turkish Standard (TSE), Ankara.

Anonymous (2015), TS EN ISO 2419 Leather - Physical and mechanical tests - Sample preparation and conditioning (ISO 2419:2012), Turkish Standard (TSE), Ankara.

Anonymous (2016a), TS EN ISO 2589 Leather - Physical and mechanical tests - Determination of thickness, Turkish Standard (TSE), Ankara.

Anonymous (2016b), TS EN ISO 3377-2 Leather - Physical and mechanical tests - Determination of tear load - Part 2: Double edge tear, Turkish Standard (TSE), Ankara.

Daniels, R. (2007), "The Scientific and Commercial Significance of Variations in Strength and Stretch in Leather", World Leather, November, 20-25.

Joseph, K. and Nithya, N. (2009), "Material flows in the life cycle of leather", Journal of Cleaner Production, $17,676-682$.

Mutlu, M.M., Ork, N., Yegin, O. and Bas, S. (2014), "Mapping the Variations of Tensile Strength over the Area of Sheepskin Leather", Annals of The University of Oradea, 15, 157-162.

Ork, N., Ozgunay, H., Mutlu, M.M., Ondogan, Z. (2014), "Comparative Determination of Physical and Fastness Properties of Garment Leathers Tanned With Various Tanning Materials for Leather Skirt Production", Tekstil ve Konfeksiyon, 24(4), 413-418.

Thanikaivelan, P., Shelly, D.C. and Ramkumar, S.S. (2006), "Gauge Length Effect on the Tensile Properties of Leather", Journal of Applied Polymer Science, 101, 1202-1209.

UNIDO (1996), Acceptable Quality Standards in the Leather and Footwear Industry, United Nations Industrial Development Organization, Vienna.

Urbanija, V. and Gersak, J. (2004), "Impact of the Mechanical Properties of Nappa Clothing Leather on the Characteristics of Its Use", Journal of the Society of Leather Technologists and Chemists, 88, 181-190.

Xiao-Lei, Z., Qing-Lan, L. and Wei-Ping, Z. (2006), "Evaluation Of Leather Handle Character By Discriminatory Two Class Analysis", Journal of the Society of Leather Technologists and Chemists, 91, 201-207. 